\title{
FEATURES OF SURGICAL ACCESS DURING VIDEOTHORACOSCOPY OPERATIONS IN THE WOUNDED WITH CHEST TRAUMA
}

\author{
Konstantyn Gerzhyk \\ Department of Thoracic Surgery \\ Military Medical Clinical Center of the Southern Region \\ 2 Pyrohovskaya str., Odessa, Ukraine, 65044 \\ ger-kostya@ukr.net \\ Vladislav Severgin \\ Department No. 4 with Oncology Course \\ Odessa National Medical University \\ 2 Valikhovskiy lane, Odessa, Ukraine, 65082 \\ thorax72@ukr.net \\ Marta Khuda \\ Department of Thoracic Surgery \\ National Military Medical Clinical Center \\ 18 Hospitalna str., Kyiv, Ukraine, 01133 \\ martakkhuda@ukr.net
}

\begin{abstract}
The aim. To improve the treatment of wounded with combat chest injury by optimizing low-traumatic surgical access using video thoracoscopy.

Materials and methods. In the period from 2014 to 2019, 103 injured were treated with video-assisted thoracoscopic surgical interventions in case of chest trauma. According to the objectives of the study, two clinical groups of victims were formed. The comparison group included $54(52.4 \%)$ victims, the main group - 49 (47.6 \%). The wounded accounted for 72 persons $(69.9 \%)$, injured $-31(30.1 \%)$. In case of wounds to the chest, the selection of victims for VTS surgical interventions and the timing of their implementation was carried out taking into account the location, type of injury and trauma, the severity of the condition of the patients, the presence of a combined wound, the possibility of two or one-lung ventilation during the intervention, the timing of admission to a medical institution with the moment of injury, the technical capabilities of military-technical operations. In staging trocars during combat chest injury, we adhere to the general rules for video-assisted thoracoscopic interventions on the chest - the rules of the "triangle". When a chest injury is involved, the port setting has its variability, which is based on the type of injury and the purpose of the surgical intervention. You can use both standard points of installation of thoracoports, and non-standard individual ones that will correspond to the set clinical goals.

Research results and discussion. High efficiency in visualization of the operating area and the technical convenience of surgical techniques have been established. This allows a rational and consistent audit of the anatomical zone of the wound. With a chest injury, the most rational sequence for conducting a pleural cavity audit is on the principle of paramount importance.

Conclusions. Features of online access - port setting for injuries to the chest depends on the area of the inlet of the gunshot. When setting ports, it is not necessary to adhere to standard points, the introduction of a thoracoport is possible at any point on the chest wall, but with the obligatory observance of the triangulation rule. The number of input ports for combat trauma to the chest depends on the technical need for a full operation. In the vast majority of military-technical operations, 3 thoracoports are enough.
\end{abstract}

Keywords: combat injuries of the chest, video thoracoscopy, thoracoport, revision of the pleural cavity.

DOI: 10.21303/2504-5679.2020.001333

\section{Introduction}

The incidence of wounds and chest injuries in peacetime reaches $7 \%$, in modern military conflicts $-7.5-11.7 \%[1,2]$. Surgical tactics for chest trauma is varied and depends on the type of injury, the time of the first medical and specialized care, the severity of the injured, the presence of complications, the technical capacity of the medical institution $[3,4]$. 
Five years of experience of the armed conflict in eastern Ukraine showed that the fire arms weapons caused the injury of special gravity (non-nuclear weapons of mass destruction - jet system of salvo fire, cassette bombs, explosive devices of high-precision action etc.). At the same time, the majority of affected chest injuries appeared to be sufficient drainage of the pleural cavity by wideband tubes, and the thoracotomy frequency reaches only 15-20\% [5]. The search for new effective methods of diagnosis and surgical treatment of the injured and traumatic chest trauma leads to an increasing use of videothoracascopical technologies at all levels of medical care in the area of ATO and JFO (Joint Forces Operatoin).

The aim. Improvement of treatment of the wounded with chest trauma by optimizing the low traumatic surgical access when using videothoracoscopy.

\section{Materials and methods}

In order to provide surgical assistance to skill with elements of specialized care, there are deployed military-mobile hospitals in the zone of the ATO and JFO in the east of Ukraine. Since July 2014 the application of endovideosurgery in the field for the treatment of trauma of the abdomen and chest was started in Ukraine for the first time. Minimally invasive operative interventions were performed using the endovideosurgical complex ECONT (manufacturer of Ukraine).

Specialists of the surgical department of the mobile hospitals have been led by both traditional and videothoracoscopy equipment, which allowed to use minimally invasive technologies as close as possible to the combat zone.

All patients were informed of their participation in the study. Each patient signed an informed consent to participate in the study. All materials were provided at a meeting of the bioethics commission at the Odessa National Medical University. Minutes of the meeting number 15 attached, data 12.03.2020

In the period 2014 to 2019 the treatment of 103 wounded were used videothoracascopical surgical intervention in the combat trauma of the chest. Two clinical groups of victims were formed according to task research. The comparison group was 54 (52.4\%) injured, the main - 49 (47.6\%). The main group included victims who underwent minimally invasive surgery. To the group of companions - victims who underwent surgical interventions through classical thoracotomy approaches. The wounded were 72 (69.9\%), injured - 31 (30.1\%). By the nature of combat damage to the thorax prevailed cases of gunshot wounds - 68 (66.0\%). Among them more often happen non-penetrating breast wounds - 40 (38.9\%) cases, including $17(34.7 \%)$ in the comparison group of wounded and 23 (42.6\%) primary group patients $\left(\chi^{2}=0.30 ; p>0.05\right.$, p.e. $\left.7 \%\right)$. Gunshot wounds penetrating injuries of the thorax were in $28(27.2 \%)$ injured. Blast chest trauma detected in 31 (30.1\%) injured: at 13 (24.1\%) men of comparison groups and 18 (36.7\%) of wounded from main group $\left(\chi^{2}=0.74 ; p>0.05\right.$, p.e. $\left.5 \%\right)$. As a type of injury in patients of both clinical groups prevailed fragmentation wounded - $26(48.2 \%)$ cases in the comparison group and $19(38.8 \%)$ - the main. In $23(22.7 \%)$ cases, there were bullet wounded.

The nature of the chest injuries was dominated by combined injuries prevailed $42(40.3 \%)$ cases: $24(44.5 \%)$ damaged in the comparison group and $18(36.7 \%)$ in the main line $\left(\chi^{2}=2,18 ; p>0,05\right.$, p.e. $\left.3 \%\right)$. Almost the same number amounted to isolated damage $-40(38.9 \%)$ cases: $18(33.3 \%)$ damaged in the comparison group and $22(44.9 \%)$ of wounded in the main group, respectively.

In case of wounds in the thorax, the selection of operative interventions and terms of their performance were carried out taking into account the localization and type of injury and injuries, the severity of patients and the presence of the combined injury, the possibility of during the intervention, duration of admission to the medical facility after injury or injury, technical capabilities of the VTS. VTS operations were conducted in the following clinical cases: 7 (13.5\%) of lung sealing operations for pneumothorax and $6(11.5 \%)$ of lung sealing operations in unstable aerostasis; $6(11.5 \%)$ operations to stop pleural bleeding continuing; $5(9.6 \%)$ stabilization of the rib frame; 15 (28.8\%) operations for coiled hemothorax; 1 (1.9\%) operation with atypical resection of the damaged lungs; 3 (5.8\%) operations regarding drained pleurisy; 9 (17.4\%) removal of foreign bodies threatening complications $\left(\chi^{2}=19,2 ; \mathrm{p}<0.001\right.$, p.e. $\left.1 \%\right)$. Single-lung ventilation with video- 
thoracoscopy operative interventions at combat injuries and injuries was performed without complications in $36(69.2 \%)$ cases.

Among the complications of the early postoperative period were impaired tightness of the lung parenchyma, which showed incomplete the straightening of the lungs and maintaining a small or medium pneumothorax for 3-5 days after being injured. In the comparison group, such complications were observed in $4(7.4 \%)$ the wounded, which required an additional surgical intervention from thoracotomy access to final sealing of the lungs.

In the primary group, these complications were observed in $2(4.1 \%)$ wounded patients, who managed to neutralize using conservative measures. There were no fatalities after the VTS. The period of stay in the hospital after the VTS operations was $16 \pm 1.2$ bed-days and depended on the severity of thoracic wounds and the presence of combined wounds. At this, the average duration of stay on treatment by the wounded in the group of comparisons was $24 \pm 1.4$ bed-day. The results indicate high efficiency of videothoracoscopy interventions in the wounded with combat (fire) injury.

At the same time, in the course of videothoracoscopy intervention in the wounded with chest trauma, there were no defined features of operational access - the location of the thoracoports, depending on the area of the firearm injury. Taking into account our experience, surgical features in minimally invasive surgical treatment of gunshot wounds, we have proposed a method of selecting the thoracoports during videothoracoscopy treatment of the chest trauma.

\section{Results}

In staging trocars for combat trauma of the chest, we adhere to the general rules for videothoracoscopy interventions on the chest - the rules of the "triangle", where the trocars are introduced at the points on the tops of a conditional triangle designed to the thorax in relation to the area of alleged operative intervention. The place of introduction of endoscopic camcorder is most often chosen in 5-6 intercostal space on the middle axillary line. This videothoracoscopy location allows to conduct a full inspection of almost all divisions of the pleural cavity and its organs, to keep under the control "working" instruments in all operative intervention. Sometimes the location of the videothoracoscop is chosen at the point, which is the most suited for the introduction of pleural drainage - 7-9 intercostal space on the middle or posterior axillary line. This position of the video camera has almost the same advantages as with the introduction of a videothoracoscopy in 5-6 intercostal space on the middle axillary line (under the conditions of use of optics with 30 degree view angle), but also allows not to make a separate incision for pleural drainage.

After the revision of the pleural cavity, it was determined the place to enter the "working" tools according to the principles of the "triangle". The trocars were introduced under the visual control of the videothoracoscop. In all cases of VTS for the intervention it was enough three thoracoports (taking into account the thoracoports for the camera) to hold the planned volume of operation. It is one $10 \mathrm{~mm}$ trocar and two $5 \mathrm{~mm}$ trocars, or two $10 \mathrm{~mm}$ trocars, one of which has an adapter for $5 \mathrm{~mm}$ endoscopic instruments. The use of two $10 \mathrm{~mm}$ trocars allows to rearrange the camera during operative intervention in order to change the viewing angle of the chest and change the placement of the "working" instruments.

We consider inappropriate, in most cases, the introduction of thoracoports because of the existing post-traumatic wounds, as the location of such wounds does not always meet the requirements for a full examination of the pleural cavity, limits the inspection and manipulation of the wound with side of the pleural cavity, as well as does not comply with the rules of aseptics, as all penetrating wounds in the combat conditions are initially contaminated. However, if during the operative intervention the introduction of the video camera or one of the "working" tools provides the most advantageous position that will allow to perform the basic stage of the operation, we consider the permissible installation of a thoracoport through the wounded canal. However, we are convinced that such manipulations should be performed only after thorough surgical treatment of the selected wounded canal.

One of the significant disadvantages of videothoracoscopy is the inability to direct palpation of anatomical structures and palpation detection of pathological changes in them, revealing and clarifying the location of the foreign bodies in the organs of the chest. The use of endoscopic ultrasound devices or endoscopic tactile mechanoreceptor apparatus is currently possible only in 
scientific and research medical institutions due to the high-cost data of devices. Therefore, in order to assess the possibility of videothoracoscopy removal of foreign bodies, it is necessary to use the obligatory procedure at the stage of preoperative training in the case of Spiral computer imaging of the chest and conduct a thorough analysis of obtained photographs using $3 \mathrm{D}$ reconstruction, with a clear representation of topographic-anatomical features of the zone of alleged operative intervention and assessment of real technical possibilities of the task execution.

In cases where the pleural cavity is conducted on a videothoracoscopy and instrumental palpation of lungs, we have not managed to confidently establish the exact location of a foreign body by using a method of direct palpation lungs: the nearest to foreign body thoracport move in the chest was introduced by a finger of the operating surgeon, and with the help of endoscopic attraumatic clamp the lung was recorded in order to prevent its displacement during palpation. Thus we were able to detect foreign bodies that could not be detected at visual inspection through the video camera.

Thus, the staging of the thorax's combat trauma has a variability that is based on the type of injury and the purpose of surgery. It can be used both the standard points of installation of thoracoports and custom-made individual, which will correspond to the supplied clinical purposes.

In the implementation of proposed methods of setting ports during thoracoscopy established high efficiency in the visualization of the operating area (area of the wounded organ) and technical convenience of surgical receptions. It is allowed to rationally and consistently conduct an audit of the anatomical zone of injury.

In the chest trauma of the most rational sequence of the pleural cavity revision we consider the principle of primary importance. First inspect pericardium, then mediastinal and lung root. If the audit detect signs of cardiac damage or trunk vessels with the correct tactic is to continue operation traditional open method. In the second place the audit of the diaphragm is carried out, in detecting its damage it is necessary to resolve the issue of the need for further videothoracoscopy, thoracoscopy or laparoscopy. And, finally, the revision of the lungs and chest wall. This revision sequence avoids common errors, when the surgeon quickly finds the output hole of the wounded canal on the parietal pleura with a wounded area of the lungs, which is subject to inner wound opening and begins its sewing, whithout the possibility of other heavier damage.

Lung collapse is required for full revision of the pleural cavity. It is achieved by the use of selective pulmonary ventilation or the creation of additional pressure in the pleural cavity by introducing gas. In the absence of emphysema and lung changes, its collaboration passes without leaving air into the lung tissue, which leads to full atelectasis of the lungs, which allows without significant difficulties to carry out operative manipulations in the pleural cavity and on the lungs. However, in the case of emphysema changes in the lungs, the collaboration may not be complete, which makes it difficult to conduct revision and operation in the pleural cavity. In these cases it is necessary to enter the carbon dioxide into the pleural space and shrink the lungs using the "working" tools to remove the air from the lungs.

\section{Discussion}

In modern thoracic surgery, surgical interventions are undergoing changes to reduce their trauma. The desire for minimally invasive interventions is explained by their advantages, first of all, in the form of reduction of pain in the postoperative period, early activation of patients, earlier return to normal physical activity [6]. This direction of improvement of surgical interventions is carried out at many pathologies of thoracic surgery. In modern medical publications much attention is paid to the features of technical support of minimally invasive interventions, types of surgical access to the chest in various pathological conditions, the peculiarities of surgical maneuvers during surgery [7].

These publications cover both diseases and injuries of the chest. The advantage of our study is that we have not only conducted a theoretical justification for the feasibility of using surgical approaches in videothoracoscopy, but also conducted a practical test [8]. The second advantage of our study was the use of various minimally invasive interventions in combat, because in the surgical experience of military field surgery, data on the use of videothoracoscopic technologies are very limited. Therefore, our experience disseminates knowledge in the section of minimally invasive surgical procedures [9]. 
The disadvantages of our work are the limited minimally invasive interventions in combat pathology of the chest, in connection with which the small amount of data obtained can not be used as a guide [10].

The number and location of thoracoports in case of combined combat wounds of the thorax remain debatable, as it is impossible to give a full assessment of the extent of damage to the internal organs of the thorax, to determine the course of the wound canal before surgery.

Promising development of endosurgery in combat pathology of the chest is the further study of the wound process in the wounded, improving the technical equipment of surgical teams of military hospitals, in-depth study of the postoperative course in the wounded with combat chest injury.

\section{Conclusions}

Features of operative access are the setting of the ports at wounds in the thorax depends on the area of the inlet fire-fuel opening. When staging ports do not necessarily adhere to standard points, the introduction of thoracoports is possible at any points of the chest wall, but with the mandatory observance of triangulation rules.

The number of the transferred ports in the chest trauma depends on the technical need for a full operation. In the vast majority of videothoracoscopy operations 3 thoracoports are enough.

Installation of thoracoports though to the wound, obtained by wounds, is not advisable, because it does not always meet the requirements for a full examination of the pleural cavity, limits the inspection and manipulation of the wound on its inner side, and does not comply with the rules of aseptic.

One of the thoracoport passages can be used for direct palpation the closest to it areas of the lungs in order to establish the exact location of the foreign bodies, which are impossible to identify visually.

\section{Conflict of interest}

The authors declare that they have no conflicts of interest.

\section{References}

[1] Zarutskyi, Ya. L., Bilyi, V. Ya. (Eds.) (2018). Voienno-polova khirurhiia: prakt. i navch. posib. dlia viisk. likariv ta likariv systemy okhorony zdorov'ya Ukrainy. Kyiv: Feniks, 544.

[2] Karimov, Sh. I., Krotov, N. F., Berkinov, U. B., Faizullaev, E. R., Dzhafarov, S. M. (2012). Videotorakoskopiia pri travmakh grudnoi kletki. Vestnik novykh meditsinskikh tekhnologii, XIX (4), 55-58.

[3] Poznanskii, S. V., Evtikhova, E. Iu., Kolbashova, Iu. N. (2012). Endovideokhirurgicheskie tekhnologii pri sochetannykh povrezhdeniiakh grudi i zhivota. Vestnik Ivanovskoi meditsinskoi akademii, 17 (4), $43-46$.

[4] Billeter, A. T., Druen, D., Franklin, G. A., Smith, J. W., Wrightson, W., Richardson, J. D. (2013). Video-assisted thoracoscopy as an important tool for trauma surgeons: a systematic review. Langenbeck's Archives of Surgery, 398 (4), 515-523. doi: http:// doi.org/10.1007/s00423-012-1016-7

[5] Schoenfeld, A. J. (2012). The combat experience of military surgical assets in Iraq and Afghanistan: a historical review. The American Journal of Surgery, 204 (3), 377-383. doi: http://doi.org/10.1016/j.amjsurg.2011.09.028

[6] Plaksin, S. A., Cherkasov, V. A. (2011). Optimizatsiia khirurgicheskoi taktiki pri travme grudi: sootnoshenie torakoskopii i torakotomii. Vestnik khirurgii im. I. I. Grekova, 4 (170), 52-54.

[7] Sigal, E. I., Zhestkov, K. G., Burmistrov, M. V., Pikin, O. V. (2012). Torakoskopicheskaia khirurgiia. Moscow: Dom knigi, 352.

[8] Borisov, A. E. et. al. (2012). Endovideokhirurgicheskie vmeshatelstva pri torakoabdominalnykh raneniiakh. Véstnik khirurgii, 171 (2), 45-49.

[9] Voskresenskii, O. V., Danielian, Sh. N., Abakumov, M. M. (2015). Videotorakoskopiia pri svernuvshemsia gemotorakse u postradavshikh s pronikaiuschimi raneniiami grudi. Praktika okazaniia neotlozhnoi meditsinskoi pomoschi, 2, 35-40.

[10] Dutta, R., Kumar, A., Das, C. J., Jindal, T. (2010). Emergency video-assisted thoracoscopic foreign body removal and decortication of lung after chest trauma. General Thoracic and Cardiovascular Surgery, 58 (3), 155-158. doi: http://doi.org/10.1007/ s11748-009-0490-5 